\title{
ENSINO DE HISTÓRIA E MEIO AMBIENTE:
}

\author{
UMA DIFÍCIL APROXIMAÇÃO
}

HISTORY TEACHING AND ENVIRONMENT: A HARD APPROACH

Ely Bergo de Carvalho ${ }^{1}$ Jamerson de Sousa Costa ${ }^{2}$

\begin{abstract}
RESUMO: $O$ presente artigo tem por objetivo perscrutar as dificuldades epistemológicas de aproximação entre o Ensino de História e o Meio Ambiente, no Brasil. A LDB (Lei 9.394/1996) estabeleceu o Meio Ambiente como um dos temas transversais da Educação Básica, e a Política Nacional de Educação (Lei 9.795/1999) estabeleceu a obrigatoriedade da Educação Ambiental em todos os níveis de ensino, não enquanto disciplina autônoma, mas como parte integrante e transversal dos cursos dados regularmente. Todavia, o Ensino de História vem se mostrando bastante impermeável a tais exigências legais. Busca entender as relações entre ensino de história e "meio ambiente" no Brasil por meio da história do marco legal e buscando apontar um elemento epistemológico geral, a saber: a forma como o mundo moderno disjuntou o social e o natural, ficando a História no campo do social, não conseguindo na prática superar a disjunção, superação essa necessária para uma compreensão verdadeiramente complexa do "meio ambiente" e da "educação ambiental', que emergem justamente da inter-relação entre o mundo social e natural.
\end{abstract}

Palavras-chave: Ensino de História. Educação ambiental. Temas transversais. Meio ambiente.

ABSTRACT: This article aims at investigate the epistemological difficulties of the approximation between the Teaching of History and the Environment, in Brazil. The "LDB" (Law 9.394/1996) established the Environment as one of the transversal themes of the Basic Education, and the National Policy of Environmental Education (Law 9.795/1999) established the need of the Environmental Education in all the regular courses. However, the Teaching of History has presented itself waterproof to these legal needs. The present article intents to understand the relationship between Teaching of History and "environment" in Brazil, through the historization of the legal mark. Moreover, this article look for identify one epistemological element in general, that is: the way the modern world separated the social and the natural, with the History stayng on the social field, not crossing this separation in practice, wich is necessary to one truly complex comprehension of the "environment" and the "environmental education", emerging from the interrelationship between the social and natural world.

Keywords: Teaching of History. Environmental education. Transversal themes. Environment.

\footnotetext{
${ }^{1}$ Professor-Adjunto de História Ambiental do Departamento de História da Universidade Federal de Minas Gerais (UFMG)

${ }^{2}$ Graduado em Comunicação, mestre em História da UFMG.
} 
"Lucien Febvre used to say 'history is man'. I on the other hand say: 'history is man and everything else'. Everything is history: soil, climate, geological movements... History is the science of the man provided it is flanked by all the human science" Fernand Braudel, 1984 apud A. Rojas, 1984.

\section{Introdução}

A História enquanto disciplina básica na formação de cidadãos, adotada como parte integrante do ensino regular dos países, como é o caso do Brasil, enfrenta inúmeros desafios. Um deles é a dificuldade relacionada à contribuição que pode dar a uma questão fortemente presente nas sociedades contemporâneas, que permeia todos os "horizontes de expectativas" (KOSELLECK, 2006) das populações humanas agora e do futuro: a questão do meio ambiente.

Posto que o debate acadêmico em História permite espaço ao diálogo de ideais e de práticas sobre a temática, no âmbito da História Ambiental ${ }^{3}$; por outro lado, o historiador que trabalha em sala de aula e que tem como objetivo ensinar História a alunos de várias idades, de crianças a jovens e adultos, enfrenta limitações para abordar o tema.

São dificuldades que permeiam problemas estruturais (baixos salários, falta de espaço adequado ao ensino, excessiva quantidade de alunos em sala de aula) e de apoio, acesso e preparação (falta de incentivo à abordagem, conhecimento precário sobre a temática e inacesso a materiais de apoio, de qualidade e em consonância com o atual momento do debate).

Entre os obstáculos, está o da tradição - ou paradigma - sobre a profissão, que coloca a História como um campo do saber "social", desvinculado do ensino sobre o saber "natural". Ora, o conceito de "meio ambiente", pelo menos como definido por Marcos Reigota (2009), busca superar essa restrição:

\footnotetext{
${ }^{3}$ A História Ambiental enquanto campo historiográfico surgiu nos Estados Unidos na década de 1970 (DUARTE, 2005; CARVALHO, 2013). Uma definição consagrada de História Ambiental é a de Donald Worster (1991), que afirma: no início do século XX, a História restringia-se à "política do passado"; no decorrer do século, os historiadores passaram a fazer de toda a sociedade objeto da História; mas "agora chega um novo grupo de reformadores, os historiadores ambientais, que insistem em dizer que temos de ir ainda mais fundo, até encontrarmos a própria terra", levando-se em conta os elementos naturais enquanto outros "sujeitos da História", capazes de condicionar significativamente a sociedade e ser condicionado por ela (WORSTER, 1991, p. 198-199).
} 
Defino meio ambiente como: um lugar determinado e/ou percebido onde estão em relação dinâmica e constante interação os aspectos naturais e sociais. Essas relações acarretam processos de criação cultural e tecnológica e processos históricos e políticos de transformações da natureza e da sociedade (REIGOTA, 2009, p. 36, grifo nosso $)^{4}$.

Sobre isso, Regina Horta Duarte (2005) explica que "construímos sentidos para o universo e a natureza [...] significando o mundo ao redor e agindo em sua transformação (positiva ou negativa) pela cultura". Ou seja, o que pensamos do mundo natural e a forma como o significamos é algo criado pela cultura da sociedade em que vivemos. Dessa forma, existem outras criações, de outras culturas, em outras sociedades, "ao longo do tempo e nas mais diversas partes do mundo" (DUARTE, 2005, p. 76-78).

Portanto, colocar a História como disciplina que aborda o social, mas que está isenta de abordar o natural, promove uma separação inconsistente, limitadora do "espaço de experiência" necessário para a construção de uma "racionalidade ambiental" que leve a humanidade a superar a atual crise ambiental (LEFF, 2006).

Diante disso, faremos um histórico da instituição da Educação Ambiental, para entender a ideia de que apenas a participação de diferentes disciplinas permite atuar de acordo com a complexidade da temática ambiental (1). Isso posto, observaremos como a separação entre disciplinas que abordam a temática social e disciplinas que abordam a temática natural reflete uma racionalidade hegemônica na sociedade ocidental desde a Modernidade (2).

A partir desse ponto, buscaremos abordar a importância de compreender a historicidade dos fenômenos para caminharmos rumo à superação de tal disjunção (3). Por fim, analisarmos como tal disjunção dificulta a aproximação entre o Ensino de História e o Meio Ambiente (4). Destacaremos, então, elementos que vêm favorecendo essa dificuldade de aproximação, a saber: a elaboração de uma História em que o ambiente é silenciado; a História de penitência; o Adestramento Ambiental; os livros didáticos; e a formação inicial e continuada.

\footnotetext{
4 Marcos Reigota defende a Educação Ambiental como uma "educação política", que forme cidadãos capazes de criticar e atuar ativamente na sociedade. Esta linha (política) é a escolhida pelo Brasil para a definir sua educação ambiental pública, conforme publicações oficiais, como o livro IEAB Identidades da Educação Ambiental no Brasil, publicado pelo Ministério do Meio Ambiente em 2004.
} 


\section{Educação Ambiental: um tema transversal}

A separação que coloca a História como disciplina que aborda o social, mas que se distancia do ensino sobre o meio ambiente, é um contrassenso. Marcos clássicos e legais da Educação Ambiental a assumem como área transversal, tanto no ensino formal, quanto não formal.

Entre esses marcos estão os debates que deram origem aos tratados da Organização das Nações Unidas para o meio ambiente. Estão também as legislações que versam sobre políticas públicas, como a Lei de Diretrizes e Bases da Educação Nacional, LDB (1996), que institui os Parâmetros Curriculares Nacionais, PCN. Essas orientações e normas reforçam que o meio ambiente deve ser tratado como tema transversal, permeando todas as disciplinas básicas, cada uma contribuindo com aquilo que seu campo de atuação possa oferecer ao entendimento da "complexidade ambiental" (LEFF, 2001); nenhuma sendo excluída ou, por outro lado, se sobressaindo às demais.

Além disso, colocar a discussão sobre o meio ambiente a cargo de apenas uma ou outra disciplina pode acarretar o que Paula Brügger (2004) define como "adestramento ambiental". A expressão se baseia no entendimento de que a Educação Ambiental serve apenas ao repasse de informações sobre o meio ambiente, quanto ao funcionamento dos ecossistemas ou à formação das paisagens, por exemplo.

Ora, mesmo que conheçamos perfeitamente esses processos, ainda assim não compreenderíamos os desafios que a problemática ambiental impõe a todos os habitantes da Terra na atualidade. Ou seja, embora tenhamos muito conhecimento sobre os processos físico-químico-biológicos do meio ambiente, ainda assim a degradação continua e, veja: ela aumenta. Esse exemplo demostra porque o meio ambiente deve ser tratado como tema transversal, em todos os níveis da educação, devido aos vieses econômicos, políticos, culturais/comportamentais - e históricos - que possui.

Pelo menos desde a Conferência das Nações Unidas sobre Meio Ambiente Humano, em Estocolmo, 1972, que tratados e documentos internacionais têm sido publicados em concordância com tal ponto. A "Agenda 21", - tratado originado da 
Conferência das Nações Unidas sobre o Meio Ambiente e Desenvolvimento, no Rio de Janeiro, 1992 - por exemplo, elabora que

a causa ambiental (...), na verdade, não se restringe a questões exclusivamente ecológicas, mas engloba também desafios como a erradicação da pobreza, afirmação global e irrestrita dos direitos humanos a consolidação da paz entre os povos. Esta é, portanto, uma obra de toda a sociedade. (ONU, 1992 In: BRASIL, 1995. p. 7).

Já a Conferência Mundial do Meio Ambiente Humano, em Estocolmo, em 1972 ressaltava que as ações humanas estavam levando a uma crise do ambiente, capaz de impactar "o bem-estar dos povos e o desenvolvimento econômico do mundo inteiro" (BRASIL, 1995). O tratado publicado após o encontro apontou para o estabelecimento de uma educação voltada ao meio ambiente, como mecanismo de ação diante do problema ambiental:

\footnotetext{
É indispensável um trabalho de educação em questões ambientais, dirigido, seja às gerações jovens, seja aos adultos, o qual dê a devida atenção aos setores menos privilegiados da população, a fim de favorecer a formação de uma opinião pública bem informada e uma conduta dos indivíduos, das empresas e das coletividades, inspiradas no sentido de sua responsabilidade com a proteção e melhoria do meio, em toda a sua dimensão humana. (BRASIL, 1995. Princípio 19 da Conferência de Estocolmo).
}

Pouco tempo depois, em 1975, a Organização das Nações Unidas realizou uma reunião, a Conferência de Belgrado, dando à Educação Ambiental a premissa de promover uma "mudança de consciência" quanto ao modo como a sociedade (ocidental) se relaciona com a natureza. A Carta de Belgrado define um programa para se criar uma "estrutura global para a Educação Ambiental", com vistas à elaboração de uma nova ética de desenvolvimento, mais justa socialmente, e voltada para a proteção do meio ambiente.

"Governos e formuladores de políticas podem ordenar mudanças e novas abordagens para o desenvolvimento [...], mas tudo isso não passa de soluções de curto prazo, a menos que a juventude mundial receba um novo tipo de educação", aponta a Carta (ONU, 1975 In: SÃO PAULO, 1994. p. 11), ressaltando o relacionamento entre estudantes, professores e comunidades nesse processo. A Carta define a aplicação tanto na educação formal, quanto na educação não formal, 
da maneira mais apropriada, a ser definida localmente, por governos e comunidades.

Em seguida, Conferência da ONU em Tbilisi, 1977, estabeleceu que fazer Educação Ambiental não era repassar informações sobre o ecossistema e seu funcionamento, mas levantar um questionamento ético e político. A partir de Tbilisi, com pressões internas e externas do movimento ambiental, entre outros fatores, foi construído um aparato institucional para viabilizar a educação ambiental no Brasil, a exemplo da maioria dos países no mundo.

No Brasil, a elaboração da Educação Ambiental mais apropriada está diretamente associada à promulgação de leis que regulamentem o assunto. A primeira é a Política Nacional do Meio Ambiente de 1981 (Lei 6.938/1981) que, entre outros aspectos, assume, como forma de preservação ambiental, a instituição da "educação ambiental a todos os níveis de ensino, inclusive a educação da comunidade, objetivando capacitá-la para participação ativa na defesa do meio ambiente" (BRASIL, Lei 6.938/1981, art. $2^{\circ}$ ).

Em 1988, a Constituição da República Federativa do Brasil dedicou um capítulo ao tema, sob o título "Do Meio Ambiente", que corresponde ao artigo 225. Composto por seis incisos, o Art. 225 diz que "todos têm direito ao meio ambiente ecologicamente equilibrado, bem de uso comum do povo e essencial à sadia qualidade de vida"; e aponta, como um dos mecanismos para que esse direito seja assegurado, a promoção de uma "educação ambiental em todos os níveis de ensino e a conscientização pública para a preservação do meio ambiente" (BRASIL, Constituição/1988, art. 225).

Uma Política Nacional de Educação Ambiental (Lei 9.795/1999) foi instituída em 1999 e regulamentada em 2002. Ela considera que "será desenvolvida como uma prática educativa integrada, contínua e permanente em todos os níveis e modalidades do ensino formal" (BRASIL, Lei 9.795/1999, art. 10), fixando a transversalidade da Educação Ambiental no país. Ainda assim, representações sobre o ambiente ainda estão presentes de maneira desigual nos livros didáticos adotados pela rede pública (CARVALHO; COSTA, 2015).

Nesse caminho, a Educação Ambiental e a História Ambiental compartilham visões semelhantes. Na História Ambiental, elementos naturais são percebidos como "sujeitos da História", agentes na interação existente entre sociedade e 
natureza, unindo o que está separado apenas pelo pensamento humano (WORSTER, 1991). A Educação Ambiental também busca desfazer essa disjunção, para uma compreensão mais complexa do ambiente, tendo em vista a produção de uma nova racionalidade ambiental.

É a partir dessa perspectiva, que se forma uma discussão mais eficiente e complexa sobre a questão ambiental, passando pela reflexão/autorreflexão sobre as formas como os indivíduos, os grupos e as sociedades têm se relacionado com o meio ao longo da História.

\section{A disjunção moderna: sociedade e natureza}

Uma professora de Biologia nos relatou que, depois de descrever os cinco Reinos da Natureza, segundo a classificação vigente (Monera, Protista, Fungi, Plantae e Animália), perguntou aos alunos do Ensino Fundamental em qual Reino os seres humanos estão incluídos? Relatando que os alunos, em geral, titubeiam para responder, disse que eles até mesmo não aceitam que pertencemos ao Reino Animália. Mais que um simples engano comum, esse evento é revelador da profunda disjunção que separa seres humanos e o mundo natural em nosso imaginário.

Simon Schama (1996) lembra com ironia que há um amplo debate sobre qual é o momento em que o mundo ocidental se afastou da natureza. Nesse ponto, afirma que: (1) "para alguns historiadores, foi o Renascimento e as revoluções científicas dos séculos XVI e XVII que condenaram a Terra a ser tratada pelo Ocidente como uma máquina que nunca quebraria"; (2) "para Lynn White Jr., foi a invenção de um arado com arreios fixos, no século VII d. C.", que iniciou uma agricultura intensiva que detonou um processo de afastamento da natureza e "selou o destino do planeta"; e (3), para os mais radicais, "só os paleolíticos habitantes das cavernas [...] integraram à natureza, ao invés de dominá-la, [...] rompida a cosmologia arcaica, na qual a Terra inteira era tida como sagrada [...]." (SCHAMA, 1996, p. 23-24).

Todavia, acreditar que a sociedade ocidental é formada por seres supraorgânicos, que estão de fora e acima da natureza, é pensar o mundo 
demasiadamente segundo a própria lógica hegemônica. Seria mais crítico e correto pensar que a sociedade ocidental-globalizada produziu uma dada maneira de pensar o mundo de forma disjuntiva, vivendo uma grande metafisica do ser humano que existiria separado do mundo natural. Mesmo com toda a tecnologia moderna, ainda somos parte do planeta Terra e da vida que lhe é constitutiva e constituidora (WORSTER, 1991, p. 211).

A história de como passamos a acreditar em tal disjunção é complexa e não menos controversa. Por exemplo, Robert Lenoble (2002) situa, em seu História da Ideia de Natureza, pelo menos três pontos de constituição de tal afastamento, a saber: 1) O "milagre grego", quando na Grécia Antiga houve a constituição a ideia que a "natureza" era um conjunto dotado de leis, portanto superando perspectivas animistas; 2) o Cristianismo, que estabelece a natureza como algo criada e portanto com um princípio e um fim, sendo que o ser humano estaria mais ligado a "cidade celeste" do que a "este mundo", no qual reinaria o pecado; 3 ) a ciência moderna que introduz a metáfora da natureza enquanto uma máquina. A chamada Revolução Científica do século XVII teria sido um ponto central de inflexão em direção de uma ruptura, como afirma o autor:

1632. Galileu pede a engenheiros que nos descubram o verdadeiro sistema do mundo. Verão que esta data merece ser fixada: a estrutura da Natureza e, conjuntamente, a estrutura da sociedade vão sofrer uma remodelação completa; o engenheiro conquista a dignidade de sábio, porque a arte de fabricar tornou-se o protótipo da ciência. O que comporta uma nova definição do conhecimento, que já não é contemplação mas utilização, uma nova atitude do homem perante a Natureza: ele deixa de olhar com uma criança olha a mãe, tornando-a por modelo; quer conquistá-la, torna-se "dono e senhor" dela. (LENOBLE, 2002, p. 260).

A natureza então passou a ser concebida como uma completa "outra", frente à emergência de uma nova atitude diante da natureza, na tentativa de domínio do mundo. Como afirma o Lenoble (2002, p. 262): "É preciso que ela se torne plenamente autônoma, 'outra', para que possamos possuir, e até subjugar esta alteridade."

Mauro Grün explica a questão a partir da obra de Descartes:

A questão [de Descartes] é simples: Como posso dominar alguma coisa da qual faço parte? A resposta é que não posso; 
consequentemente, não posso fazer parte da natureza. Se pretendo dominá-la, preciso me situar fora dela. Assim, Descartes consegue legitimar a unidade da razão às custas [sic] da objetificação da natureza. (...) É na base desse dualismo que encontramos a gênese filosófica da crise ecológica moderna (...). A natureza e a cultura passam a ser duas coisas muito distintas. (GRÜN, 2000, p. 34-35, grifo nosso).

Muitos interpretam que, no coração da crise civilizatória por que passa a sociedade globalizada, está o fato, justamente, de que no mundo moderno se operou uma disjunção entre sociedade humana e mundo natural (MORIN, 1999). E tal fato não se deve apenas a mudança em nossa forma de pensar: a própria organização da sociedade moderna, como demonstrou Polanyi (2000), está pautada em tal disjunção, pois "desencapsulou o mundo natural da sociedade", de tal forma que os indivíduos, isolados de um lado, e a natureza, tomada como recurso natural por outro, estivessem disponíveis para a venda no mercado.

Daí que alguns autores proporem uma reapropriação social da natureza e a construção de uma racionalidade ambiental como forma de sairmos da atual crise civilizatória (LEFF, 2006). Mas, tal debate vai além do objeto deste texto. O que deve ser destacado aqui é que fazer as conexões, ruma a superação da forma disjuntiva que hegemonicamente vemos o mundo natural e social, passa por entender ambos de forma processual, ou seja por entender sua historicidade.

\section{Historicidade das relações humanas com os ambientes}

A dicotomia natural versus social/cultural/histórico prejudica não somente a nossa compreensão do "social", mas também do "natural". A ideia de uma "natureza intocada", sem interferência humana, é enganosa - por exemplo grande parte das matas "originais" já tiveram alguma influência humana no passado; e, em termos mais abrangentes, podemos dizer que o próprio clima pode, segundo determinadas pesquisas, ter sofrido a influência antrópica e, portanto, agir sobre o mudo natural a partir dessa interferência. Da mesma forma, a ideia de se buscar entender as sociedades humanas apenas pelos seus elementos sociais, como se estas não fizessem parte de um ecossistema, também leva ao entendimento parcial da realidade. 
Na verdade, conforme defende Francisco Carlos Teixeira da Silva (1997), referindo-se à história das paisagens, a noção de uma paisagem natural em oposição à paisagem social deve ser abandonada, uma vez que tal separação é arbitrária, devendo ser substituída em favor de um continuum. Um bom exemplo, dado pelo autor, é a paisagem típica da área litorânea do Rio de Janeiro, no século XVIII, composta de imensos canaviais, envolvendo "sertões" - ilhas de mata nativa, e pontilhadas de roças:

As possibilidades técnicas, o nível de disponibilidade demográfica do trabalho e o direcionamento da produção impunham um sistema de uso dos recursos naturais. [...] normas, escritas ou não, garantiam os direitos de uso da terra e as normas de conservação do [...] 'sertão'. O imperativo de se dispor de energia - em uma época em que a lenha era a fonte básica - regulava e detalhava o uso da floresta. Ora, a aparente polarização campo/floresta mostrar-se-ia, desta forma, como complementaridade: mesmo que nunca houvesse sido cultivada, $[\ldots]$ no Rio de Janeiro, a floresta era produto das normas então vigentes. A sua própria existência, em meio a áreas agriculturáveis, já era, em si, um resultado do direito. Além de tudo, a ação constante do homem catando gravetos, recolhendo frutos, caçando animais ou controlando incêndios - para só citar trabalhos 'leves' no interior do bosque - alterava em profundidade o comportamento das populações vegetais. Tudo somado implicava que a floresta já não era, desde há muito, 'natural'. Assim, a distinção formal entre paisagem natural e paisagem cultural mostra-se [...] bastante prejudicial a um amplo entendimento da relação homem/natureza (SILVA, 1997, p. 209).

Eis um bom exemplo de que, quando fazemos uma abordagem processual, a interação entre os elementos ditos "naturais" e "sociais" tende a dissolver a disjunção. Ou seja, entender a historicidade material e simbólica dos fenômenos é fundamental para uma compreensão que vá além da disjunção que conforma nossa forma hegemônica de ver o mundo.

A História e outras disciplinas tradicionalmente associadas ao "social", como a Filosofia e a Sociologia têm trabalhos em que apresentam diferentes formas como os seres humanos se comportam em relação ao meio ambiente, em diferentes contextos onde vivem. Para entender como foram as relações, muito variadas entre si, das populações humanas com o meio ambiente, esses trabalhos trazem diferentes visões quanto às formas desse relacionamento, em contextos temporais e espaciais distintos. 
Trabalho marcante é o de Jared Diamond (2012) estudo no qual conta a história de populações que colapsaram suas próprias formas de vida, ao manter relações insustentáveis com o meio.

Em contraponto a tal autor, vários cientistas questionaram as teses de Diamond afirmando que as sociedades não-ocidentais estudadas por ele foram principalmente vítimas do processo de exploração colonial (MCANANY; YOFFEE, 2010). Tal crítica parece, por vezes cair na perspectiva de existirem "bons selvagens ecológicos", representação que surfa, em grande parte, na imagem positiva das comunidades extrativistas e de pequenos agricultores que foi produzida pelo movimento ambiental, ao identificar esses modos de vida como estando em uma suposta "harmonia com a natureza" e pelos movimentos sociais que incorporaram tal argumento legitimador em sua autorrepresentação.

Ademais, devemos lembrar sempre no potencial de transformação que tais "comunidades tradicionais" têm de seu ambiente, não estando elas em "harmonia" com a natureza. Conduto, por outro lado, a busca de mecanismos de colapso de Diamond pode ser questionada, também, por não conseguir fugir da racionalidade do pensamento Ocidental, e está demasiadamente preso a uma concepção de ser humano como um Homo economicus, movido por uma racionalidade mercantil individualista.

E não é estranho que uma parte dos estudos das ciências ambientais atuais compartilhe uma visão de Homo devastans, ou seja, uma visão de que toda interação com o ambiente, feita pelo ser humano, vai gerar uma redução na biodiversidade, "destruindo" a natureza. Ambas as noções cometem o mesmo erro de partir de uma "natureza humana" (destruidora ou preservadora) em relação ao meio ambiente, não reconhecendo a contingência, a criatividade, as racionalidades que podem criar diferentes formas de com-viver ou de destruir os ambientes em que vivemos (BALÉE, 1998; 2003).

A lição que se tira é sobre como a nossa maneira de ver e de nos relacionarmos com o ambiente não é algo "natural", no sentido de que pensamos, agimos e reagimos em relação ao ambiente de uma maneira única e imutável, inerente aos seres humanos em geral; mas sim algo construído culturalmente, diante de processos históricos, sociais e político-econômicos próprios do contexto espacial/social e do período em que cada grupo humano está envolvido. 
Um grande desafio, portanto, é inserir de forma crítica e construtiva, a natureza nas aulas de História. Isso passa pela formação de professores, pela incorporação do tema nos livros didáticos e pela melhoria estrutural que possa dar condições aos professores de desenvolverem o tema nas suas classes.

Outro desafio, esse mais no âmbito acadêmico, passa pela definição de em quais aspectos a História pode contribuir para o tratamento da questão ambiental na formação dos alunos, para que não caia num "adestramento", nem no que Schama (1996) chamou de "penitência": uma História que narra como as sociedades humanas, especialmente aquelas capitalistas, destruíram o meio ambiente - salvo exceções, basicamente caracterizadas pelas chamadas sociedades tradicionais. Um erro, referente a uma generalização que coloca uns humanos como bonzinhos, outros como maus.

Um dos pontos enfatizados na História Ambiental, como caminho para melhoria desta, é trabalhar as relações presentes entre seres humanos e ambientes. Ou seja, deixar claro, que as sociedades humanas vivenciaram diferentes formas de relacionamento com o ambiente: e que a relação que levou, em maior ou menor grau, à crise ambiental contemporânea não é necessariamente um comportamento intrínseco ao ser humano (portanto, destruidor e mau), mas algo culturalmente construído. Essa ênfase pode ajudar a reconstruir as formas de reflexão e, em seguida, de ação sobre o meio ambiente - tanto para adultos, quanto para aqueles que estão em formação nas escolas básicas.

A História, assim, mais do que relatar exaustivamente as consequências negativas da relação humano-ambiente ao longo da História, favorecendo a separação entre as duas instâncias (humano e natural), pode apresentar diferentes formas históricas de convívio com a natureza, dando ferramentas para um pensamento crítico e construtivo, que possa dar novos ares a essa relação. Não aceitando uma Educação Ambiental que reduz sua atividade a um julgamento de valor que condena "o ser humano", em abstrato. Pelo contrário, a História pode contribuir para, manter aberto e ampliar nosso horizonte de expectativas a partir de nosso espaço de experiência (KOSELLECK, 2006). Ou, ainda nas palavras de Paulo Freire:

Gosto de ser homem, de ser gente, porque sei que a minha passagem pelo mundo não é predeterminada, preestabelecida. Que 
e o meu 'destino' não é um dado mas algo que precisa ser feito e de cuja responsabilidade não posso me eximir. Gosto de ser gente porque a História em que me faço com os outros e de cuja feitura tomo parte é um tempo de possibilidades e não de determinismo. Daí que insista tanto da problematização do futuro e recuse sua inexorabilidade (FREIRE, 2002, p. 58-59).

\section{Dificuldades de aproximação entre o Ensino de História e o Meio Ambiente}

A dificuldade de trabalhar temas transversais está ligada diretamente à adversidade de realizar um trabalho realmente interdisciplinar, em que todas as disciplinas contribuam para a formação de um conhecimento ambiental. Há, pelo menos, três obstáculos para Educação Ambiental nas escolas, que levam à sua pouca expressividade:

a) a 'questão ambiental' é tratada como mais um entre outros 'problemas' a serem 'solucionados' pela escola, o que retira a dimensão sistêmica da problemática ambiental contemporânea e superestima a capacidade da escola de resolver problemas que são mais amplos que seu âmbito de atuação; b) a crônica carência material e de condições de trabalho, em especial nas escolas públicas - baixos salários e salas superlotadas que dificultam, em muito, por exemplo, um trabalho interdisciplinar nas escolas; e c) a estrutura fragmentada do conhecimento moderno, voltado para o controle e não para o diálogo com a natureza, que é reproduzido nas escolas. (CARVALHO, 2012, p. 364).

Todavia, não há como abordar todas essas variáveis aqui, uma vez que o foco está em apontar problemas enfrentados na disciplina de História, quanto aos temas ambientais, atentando para as especificidades desta disciplina. Circe Bittencourt (2003) afirma que um dos problemas para a ausência da natureza nas aulas de História é a falta de métodos para introduzir a Educação Ambiental neste contexto. Essa é a mesma preocupação de outros autores, que apresentam suas contribuições: Por exemplo, Gilmar Arruda propõe que os professores de História devam aprender a sair da sala de aula e "usar os pés" em suas aulas (ARRUDA, 2008), Marcos Gerhardt e Eunice S. Nodaria (2010) buscaram arrolar táticas de abordar temas ambientais na aula de História ou, ainda, há autores que têm 
efetuado uma análise crítica visando a reformular, ambientalmente, os livros didáticos da área (ALMEIDA; COLACIOS, 2011; CARVALHO, 2012).

Obviamente que a tarefa de superar tal disjunção não cabe apenas a academia, mas passa por todo um sistema de ensino, afinal o professor de História do ensino básico é um dos produtores de um saber escolar, antes de ser mero transmissor do conhecimento acadêmico. Esse saber vem em parte da apropriação do próprio saber acadêmico, levado aos bancos escolares.

Diante disso, abordaremos cinco elementos que dificultam a aproximação entre o Ensino de História e a Educação Ambiental, todos permeados por nossa tese central do papel central ocupado na disjunção sociedade versus natureza como elemento fundante das dificuldades de trabalhar "meio ambiente" no ensino de história. Vamos abordar cada um deles, a partir de agora.

\section{A) História em que o meio ambiente é silenciado}

Uma crítica pertinente atualmente é como a narrativa histórica apresentavam o meio ambiente apenas como um elemento passivo: ora como pano de fundo para as importantes aventuras e desventuras humanas; ora como vítima destes. Entender, escolher e apresentar as situações em que o meio ambiente está presente, mas em que ele também age sobre a história da humanidade, é um passo em direção da superação de uma perspectiva disjuntiva de mundo (SOFFIATI, 1990).

Em um estudo de caso, a comparação entre a forma como o mundo natural é representado em manuais de História e Geografia, é bastante ilustrativa de tal silenciamento do mundo natural:

A obra História e Geografia de Mato Grosso é extremamente reveladora por reunir duas disciplinas: a primeira parte da obra é dedicada à História, e a segunda à Geografia. A 'questão ambiental' é claramente tratada pelo autor na parte do livro reservada para a Geografia. Na parte destinada à História o mundo natural aparece quase como uma 'paisagem imóvel' em que os fatos humanos ocorrem. Cita-se apenas, e de forma pontual, as 'enchentes' no século XIX, 'extrativismo vegetal' no início do século XX e até a criação da 'Secretaria de Meio Ambiente' em meados da década de 1980. Mas as apreciações sobre o ambiente tendem a uma descrição, não uma problematização da relação entre seres humanos e o mundo natural. (...) Na parte do livro que trabalha com a Geografia de Mato Grosso há 
uma abordagem histórica em que o mundo natural aparece como um agente ativo nos processos históricos (CARVALHO, 2014a, p. 30-31).

Mesmo, em casos extremos, como um estudo sobre os manuais escolares de história de Mato Grosso anteriores a 1990, que silenciam explicitamente sobre árvores, animais, rios e montanhas, procurando produz uma imagem moderna e urbana do Estado, há aí uma representação do que seja a natureza desejada ou indesejada, por determinados grupos sociais, que queriam afastar a pecha de ser um lugar bárbaro e modernizar a região por meio da migração e colonização o que implicava na expropriação das populações "tradicionais" locais. De tal forma que:

A 'corporação' dos historiadores participou e participa dos investimentos simbólicos para entender, de determinadas formas, os ambientes e os seres humanos, contribuindo para legitimar a apropriação de alguns ou a expropriação de outros. Assim, se o mundo natural interfere no rumo da História humana, a História contada pelos seres humanos também interfere no mundo natural. A natureza sempre esteve na História, pois, entre outros, a disciplina tem um papel ativo no jogo de produção da memória social (CARVALHO, 2014b, p. 179).

Ou seja, mesmo quando silenciada a natureza nunca está ausente das aulas de História.

\section{B) História de penitência}

Atualmente, quando se é possível olhar para trás e ver de forma analítica o trabalho dos primeiros historiadores ambientais, são feitas certas críticas a eles ainda que ressalte, constantemente, sua contribuição para o desenvolvimento dos estudos históricos, e para a criação e ampliação de um campo próprio dentro da História.

Uma delas é quanto ao caráter "penitencial" (SCHAMA, 1996, p. 23) dos primeiros trabalhos de História Ambiental. Ou seja, elaborando uma narrativa em o ser humano parece um "erro da natureza" que esteve sempre a destruí-la. Assim, podemos concluir que existem desafios para os historiadores em sala de aula - e para a própria História Ambiental -, de inserir a discussão ambiental nos estudos históricos em pelo menos três etapas fundamentais: colocar o ambiente em meio as narrativas, o que significa torná-lo presente (1); apresentar como ele age sobre 
as sociedades humanas, e não apenas o contrário (2); e recriar essa interação sem dualismos, como humano-agressor/natureza-vítima (3), refletindo sobre as formas como diferentes povos criaram diferentes formas de interagir com a natureza, o que possibilita criticar a própria conduta hegemônica das sociedades ocidentais atuais, em relação ao ambiente. Afinal, como adverte Schama:

Se toda a história da paisagem no Ocidente de fato não passa de uma corrida insensata rumo a um universo movido a máquina, sem a complexidade de mitos, metáforas e alegorias, no qual o árbitro absoluto do valor é a medição e não a memória, no qual nossa inventividade constitui nossa tragédia, então realmente estamos presos no mecanismo de nossa autodestruição. (SCHAMA, 1996, p. 24 - grifo nosso).

\section{C) O Adestramento Ambiental}

Outro problema do ensino da História em relação à Educação Ambiental é quanto aos obstáculos enfrentados por diretores e professores, especialmente estes, na preparação de aulas voltadas ao meio ambiente. Muitas vezes, cai-se no que Brügger (2004) chamou de "adestramento" ambiental.

Explica-se sobre o que fazer, e o que não fazer, para proteger o meio ambiente; reduzindo o "meio ambiente" ao ensino de ecologia e geografia física, sem, no entanto, criar uma visão crítica e estreitar os laços de interação entre os seres humanos e o ambiente. Em outras palavras, unir o que nunca esteve separado, a não ser na mente humana (WORSTER, 1991, p. 206).

Esse adestramento, por outro lado, pode ter um efeito reverso (e também perverso), favorecendo a visão de que a natureza é e sempre foi vítima da ação de seres humanos, que estão fora do ambiente, como seres a parte da natureza que os cerca. Note que, além disso, o "adestramento" pode, inclusive, prejudicar uma mudança de pensamento e postura em relação ao meio ambiente, posto que gera a incompreensão das complexas conexões de questões ambientais.

Para uma educação política, que forma cidadãos para atuarem na sociedade em que vivem, é necessário contribuir para reflexões críticas e para a atuação transformadora, que sejam relevantes ao local de vivência (REIGOTA, 2009). O "adestramento" pode ir ao oposto, reforçando conceitos e comportamentos sobre o meio ambiente, que se veem como degradantes. 
A esse respeito, um exemplo, já citado por Brügger (2004, p. 100), é o das crianças envolvidas em uma gincana escolar. Elas precisavam coletar o máximo de materiais recicláveis e leva-los aos seus professores, a fim de ganharem pontos na competição. De incentivo a refletir sobre a questão ambiental do consumismo, isso fez com que alunos estimulassem seus pais a comprarem e consumirem mais produtos, para terem mais materiais, provocando o efeito contrário do que se esperava com essa ação.

\section{D) Livros didáticos}

Um terceiro problema está relacionado aos materiais didáticos, produzidos sem nenhum, ou com poucas referências às diferentes formas de interação entre as sociedades e o meio ambiente nos diferentes contextos históricos. É comum ver a incorporação do tema meio ambiente nos livros didáticos de História pelo acréscimo, em quadros (box) separados do conteúdo principal, com curiosidades e outras informações sobre o ambiente (CARVALHO, 2010; CARVALHO; COSTA, 2015), sem a proposta de uma reflexão sobre a questão ambiental (SOARES; NOVICKI, 2006).

Nos materiais didáticos, o meio ambiente é relacionado a duas áreas em especial $^{5}$ : uma perspectiva que coloca o conhecimento sobre o meio ambiente relacionado como tema de cidadania; e como um tema contemporâneo, geralmente nas unidades e/ou capítulos que tratam do mundo pós-Segunda Guerra Mundial (CARVALHO; COSTA, 2015).

Quando o livro arrola o meio ambiente com outros "temas de cidadania", tal como gênero, raça, etc. tira dele seu caráter sistêmico, sendo mais um tema que "a educação tem que resolver", o que superestima a esfera de transformação possível em um ambiente escolar. E a redução da questão ambiental a um tema atual, retira seu caráter histórico, afinal, a relação com o meio ambiente é permanente na própria História humana. Mesmo que as ideias de meio ambiente

\footnotetext{
5 Conforme constatado na pesquisa que deu origem ao artigo "Representações de meio ambiente e Educação Ambiental em História e em Geografia: uma análise dos guias de livros didáticos do PNLD 2012" (CARVALHO; COSTA, 2014), obra citada neste trabalho, em que os autores analisam os guias do Governo Federal para os professores de História e de Geografia do Ensino Médio.
} 
ou de natureza sejam históricas, passiveis de serem localizados no espaço e no tempo dentre as criações humanas.

É neste ponto em que essa disciplina poderia se insere de forma privilegiada, ao historicizar tal relação. Para isso, deve assumir o papel da natureza na formação e continuidade das sociedades humanas e o papel das sociedades humanas ao produzirem material e simbolicamente os ambientes.

\section{E) Formação inicial e continuada}

Uma série de autores tem apontado que o debate sobre Educação Ambiental, apesar de obrigatório, e do desenvolvimento do campo de pesquisa nas últimas duas ou três décadas, aparece muito pouco nas aulas de História (BITTENCOURT, 2003; CARVALHO, 2012).

A forma como a relação sociedade e natureza é tratada, seja em disciplinas específicas ou nas disciplinas básicas dos cursos de graduação, em geral, não permite ao licenciado abordar de forma articulada com outas disciplinas tal temática. Embora o campo de pesquisa esteja mais ou menos desenvolvido hoje, no Brasil e no exterior, essa abordagem do meio ambiente nas aulas de História tem sido rara. Mesmo professores que passaram por disciplinas clássicas como Geo-História, ainda tem sua prática educacional fortemente marcada por uma perspectiva disjuntiva, em que "a natureza não aparece nas aulas de História" (CARVALHO, 2012).

Contudo, pesquisa sobre a prática docente de professores de História ${ }^{6}$ mostra que não podemos fazer jamais tabula rasa do saber escolar e das experiências de professores que por meio de uma história problema, conseguem em suas disciplinas conectar o presente e o passado, que conseguem narrar uma História em que o ser humano não é tudo. Como revela a abordagem de entrevistas com professores:

[...] Há também presente na narrativa das memórias dos professores a representação de práticas educacionais que vão além de um 'adestramento ambiental'. A complexidade dessas práticas

\footnotetext{
${ }^{6}$ Estudo de História Oral com professores de História do Mato Grosso, que deu origem ao artigo "'A natureza não aparecia nas aulas de História': lições de educação ambiental aprendidas a partir das memórias de professores de História" (CARVALHO, 2012), obra citada.
} 
de educação ambiental, nas quais há uma tentativa, mesmo que não sistemática, de superação das disjunções e da adoção de uma abordagem mais complexa, indica o quão importante é considerar a memória e as práticas dos professores em projetos de formação continuada, de forma a não reproduzir uma racionalidade burocrático-técnica que, em nome da eficácia produtivista e/ou da conscientização, silencia as experiências do outro como um 'não saber'. Há que se considerar a trajetória de formação desses professores, não enquanto algo que deve ser eliminado para ser substituído pelo saber acadêmico, mas deve ser reconhecida a riqueza de experiências necessárias para construir uma educação ambiental que não será uma fórmula universal, mas, sim, práticas particulares conectadas, pelo menos essa é a aposta aqui (CARVALHO, 2012, p. 374).

\section{Considerações finais}

Um primeiro problema do ensino da História em relação à Educação Ambiental é, portanto, o da separação entre social e natural, observada na cultura ocidental-globalizada contemporânea. História, enquanto disciplina que aborda a política-economia-sociedade do passado, estaria isenta de falar sobre o meio ambiente. Tanto professores de História, quanto de outras disciplinas, ainda mantêm essa ideia de que o campo da História está apartado do meio ambiente e, assim, poucas considerações tem a fazer sobre o tema.

Mas com os Parâmetros Curriculares Nacionais (PCN) de 1996, coloca-se em foco a abordagem transversal do meio ambiente pelas disciplinas escolares. Tal proposta foi inicialmente construída pelos documentos internacionais que versam sobre a Educação Ambiental, principalmente o que foi elaborado na Conferência de Tbilisi em 1977.

A Conferência Internacional, fomentada pela ONU, em Tbilizi, 1977, sobre esse tema já estabelecia em seus princípios que a Educação Ambiental não era repassar informações sobre o ecossistema e seu funcionamento, mas deveria ser um questionamento ético e político, ao que preferimos chamar de racionalidade moderna, de domínio da natureza e de ampliação ad infinitum do consumo (CARVALHO, 2010, p. 7).

Dessa forma, a História é exatamente a disciplina privilegiada para o alcance dos objetivos da Educação Ambiental, qual seja uma transformação na visão e nos valores da sociedade contemporânea, marcadamente a sociedade ocidental, voltada para o mercado global. 
A História permite comparações entre passado e presente, com vistas à construção de ideias críticas e que desmontam a naturalização do comportamento atual, sobre o meio ambiente, assim como sobre todas as coisas. Ou seja, de que nosso modo de ser e agir é e sempre foi assim, que isso é natural: a História mostra exatamente que, em outros tempos e lugares, sociedades humanas agiram diferentemente em relação à natureza, e que uma mudança é sempre possível, uma vez que essas condutas são construídas pelos humanos, de acordo com o contexto (espacial, temporal e social/cultural) em que vivem.

Talvez, em uma sociedade que aprenda a co-habitar no planeta Terra (MORIN; KERN, 2005), o meio ambiente consiga ser efetivamente tema transversal na educação. Ou seja, talvez quando aprendermos que integramos o mundo em que vivemos, possamos construir um conhecimento em que o mundo não esteja lá fora, mas em que nós estejamos nele. A inserção do meio ambiente como tema transversal é parte desse esforço, de produção de uma educação ambiental que fomente uma nova racionalidade ambiental, superando a disjunção que ainda organiza a forma hegemônica de "ser no mundo" da sociedade globalizada em que vivemos.

\section{Referências}

ALMEIDA, J. P. de; COLACIOS, R. D. (Org.). Ambiente e Sociedade: trajetos de História, Ecologia Política e Educação Ambiental. Gravataí-RS: Escritos, 2011. Ebook.

ARRUDA, G. Natureza: uma nova "sala de aula" para o ensino de História. In: OLIVEIRA, M. D. de; CAINELLI, M. R.; OLIVEIRA, A. F. B. de. (Org.). Ensino de História: múltiplos ensinos e múltiplos espaços. Natal: EDFURN, 2008. p. 59-67.

BALÉE, W. Advances in Historical Ecology. New York: Columbia University Press, 1998.

Diversidade amazônica e a escala humana do tempo. SIMPÓSIO DE ETNOBIOLOGIA E ETNOECOLOGIA DA REGIÃO SUL, 2003, Florianópolis. Anais. Florianópolis: UFSC, 2003. p. 14-28.

BITTENCOURT, C. M. F. Meio ambiente e ensino de História. História \& Ensino. Londrina, v. 9, p. 63-96, out. 2003.

BRASIL. Cap. VI: Do Meio Ambiente. In: Constituição da

República Federativa do Brasil. Brasília: Senado Federal, 1988. 
BRASIL. Identidades da educação ambiental brasileira. Brasília: MMA/DEA, 2004.

BRASIL. Lei da Política Nacional de Educação Ambiental. Lei 9.795 de 27 de abril de 1999.

BRASIL. Lei da Política Nacional do Meio Ambiente. Lei 6.938 de 31 de agosto de 1981.

BRASIL. Parâmetros curriculares nacionais: introdução aos parâmetros curriculares nacionais. Brasília: MEC/SEF, 1997.

BRÜGGER, P. Educação ou adestramento ambiental. 3.ed.rev.eampl. Florianópolis: Letras Contemporâneas, 2004.

CARVALHO, E. B. de. "A natureza não aparecia nas aulas de História": lições de educação ambiental aprendidas a partir das memórias de professores de História. História Oral. v. 15, n. 1, p. 357-379, jan./jun. 2012.

CARVALHO, Ely Bergo de. A quem serve a História? Livros de popularização da História de Mato Grosso, Brasil, 1990-2012. HIb: Revista de Historia Iberoamericana, v. 7, n. 2, p. 20-41, 2014a.

. Uma História a serviço da destruição? Livros de História e a modernização de Mato Grosso, Brasil, 1964-1992. HALAC Historia Ambiental Latinoamericana y Caribeña, Belo Horizonte, v. 3, n. 1, p. 155-179, set. 2013 fev. 2014b.

História Ambiental e o Ensino de História: uma difícil aproximação. In: FANAIA, CEREZER \& RIBEIRO (Orgs.). Escrita da História. Cáceres: Editora da UNEMAT, 2010. p. 209-219.

. Uma História para o futuro: o desafio da educação ambiental para o ensino de História. Revista História Hoje, v. 5, n. 14, p. 1-10, 2011.

; COSTA, Jamerson de Sousa. Representações de meio ambiente e Educação Ambiental em História e em Geografia: uma análise dos guias de livros didáticos do PNLD 2012. In: $14^{\circ}$ SEMINÁRIO NACIONAL DE HISTÓRIA DA CIÊNCIA E DA TECNOLOGIA, 2014, Belo Horizonte. Anais. BH: UFMG, 2015. Disponível: < http://www.14snhct.sbhc.org.br/conteudo/view?ID CONTEUDO=800>

DEAN, W. A ferro e fogo: a história e a devastação da Mata Atlântica brasileira. São Paulo: Companhia das Letras, 1996.

DIAMOND, J. Colapso: como as sociedades escolhem o fracasso ou o sucesso. 8 ed. Rio de Janeiro: Record, 2012. 699 p.

DUARTE, R. H. História \& Natureza. Belo Horizonte: Autêntica, 2005.

FREIRE, P. Pedagogia da autonomia: saberes necessários à prática educativa. 24. ed. Rio de Janeiro: Paz e Terra, 2002. 
GERHARDT, M.; NODARI, E. S. Aproximações entre História Ambiental, Ensino de História e Educação Ambiental. In: BARROSO, V. L. M.; et. al. Ensino de História: desafios contemporâneos. Porto Alegre: EST, 2010. p. 57-72.

GRÜN, M. Ética e Educação Ambiental: a conexão necessária. 3 ed. Campinas: Papirus, 2000.

KOSELLECK, R. Futuro passado: contribuição à semântica dos tempos históricos. Rio de Janeiro: Contraponto / PUC-RIO, 2006.

LEFF, E. Construindo a História Ambiental da América Latina. Esboços. Florianópolis, v. 13. Dossiê História Ambiental. p. 11-29, 2005.

. Epistemologia Ambiental. São Paulo: Cortez, 2001.

- Racionalidade ambiental: a reapropriação social da natureza. Tradução:

Luis Carlos Cabral. Rio de Janeiro: Civilização Brasileira, 2006.

LENOBLE, R. História da Ideia de Natureza. Lisboa: Edições 70, 2002.

MCANANY, P.; YOFFEE, N. (Ed.). Questioning Collapse: Human Resilience, Ecological Vulnerability and the Aftermath of the Empire. Cambridge: Cambridge University Press, 2010.

MORIN, E. Ciência com consciência. 3. ed. Rio de Janeiro: Bertrand Brasil, 1999. Sulina, 2005. ; KERN, Anne Brigitte. Terra-Pátria. Tradução: Paulo Neves. Porto Alegre:

ONU. A Carta de Belgrado: Uma estrutura global para a Educação Ambiental - 13 a 22 de outubro de 1975. In: SÃO PAULO. Educação ambiental e desenvolvimento: documentos oficiais. São Paulo: Secretaria do Meio Ambiente/Coordenadoria de Educação Ambiental, 1994.

ONU. Agenda 21. In: BRASIL. Conferência das Nações Unidas sobre Meio Ambiente e Desenvolvimento: Agenda 21. Brasília: Câmara dos Deputados/Coordenação de Publicações, 1995.

ONU. Conferência das Nações Unidas sobre o Meio Humano. In: BRASIL. Conferência das Nações Unidas sobre o Meio Ambiente e Desenvolvimento: Agenda 21. Brasília: Câmara dos Deputados/Coordenação de Publicações, 1995.

ONU. Conferência Intergovernamental sobre Educação Ambiental. In: SÃO PAULO. Educação ambiental e desenvolvimento: documentos oficiais. São Paulo: Secretaria do Meio Ambiente/Coordenadoria de Educação Ambiental, 1994. Série Documentos.

POLANYI, K. A grande transformação: as origens da nossa época. 8. ed. Rio de Janeiro: Campus, 2000.

REIGOTA, M. O que é Educação Ambiental. 2. ed. São Paulo: Brasiliense, 2009. 
SCHAMA, S. Paisagem e Memória. São Paulo: Companhia das Letras, 1996.

SILVA, F. C. T. da. História das paisagens. In: CARDOSO, Ciro Flamarion; VAINFAS, Ronaldo. (Org.). Domínios da História: Ensaios de teoria e metodologia. Rio de Janeiro: Campus, 1997. p. 203-216.

SOARES, A. de A. R.; NOVICKI, V. Educação ambiental através de livros didáticos de história do segundo segmento do ensino fundamental. In: ENCONTRO ANUAL DA ASSOCIAÇÃO NACIONAL DE PÓS-GRADUAÇÃO E PESQUISA EM EDUCAÇÃO, 2006, Caxambu. Anais. Caxambu: ANPED, 2006.

SOFFIATI, A. A Ausência da Natureza nos Livros Didáticos de História. Revista Brasileira de História, São Paulo, v. 9, n. 19, p. 43-56, set.1985/fev. 1990.

THOMAS, K. O homem e o mundo natural: mudanças de atitude em relação às plantas e aos animais (1500-1800). São Paulo: Companhia de Bolso, 2010. 537 p.

WORSTER, D. Para fazer História Ambiental. Estudos Históricos, Rio de Janeiro, v. 4, n. 8. p. 198-215, 1991. 